\title{
Research on the Construction of Mixed Teaching System from the Perspective of Multiple Subjects
}

\author{
Fang Liu* \\ School of Public Administration \\ Shandong Normal University \\ Jinan, China
}

\author{
Huihui $\mathrm{Xu}$ \\ School of Public Administration \\ Shandong Normal University \\ Jinan, China
}

\begin{abstract}
The three-helix theory provides a new theoretical basis for the breakthrough construction of the hybrid teaching system. This paper innovatively analyzes from the perspective of multiple subjects and attempts to provide a theoretical basis and practical suggestions for the construction of a hybrid teaching system. Firstly, this paper combs the development process of the hybrid teaching system and defines the hybrid teaching system from the perspective of multiple subjects. Secondly, the article proposes a four-party co-construction mechanism of the hybrid teaching system, forming a coordinated guarantee mechanism for the participation of schools, enterprises, governments and social organizations. It constructs a hybrid teaching system across schools, multi-subjects and the whole process. Finally, the article rationally points out that the participation of multiple subjects in the construction of a mixed teaching system may have difficulties in enthusiasm, participation and coordination. This system is of great significance for enriching the theory and practice of hybrid teaching. It has great room for promotion in the context of the knowledge society, wisdom education and multi-subject governance, but its difficulties need to be overcome, and the practical results need to be further verified.
\end{abstract}

Keywords-Multiple subjects; Mixed teaching system; Three Helix Theory; Four-party co-construction mechanism

\section{INTRODUCTION}

In the context of digitalization and globalization, the hybrid teaching movement has swept through all areas of world education, from the traditional asynchronous online course AOC (Asynchronous Online Course ) [1] to the open courseware project and video open class represented by the OCW (Open Course Ware ) [2] program, then to the online mass education MOOC (massive open online courses) [3]. Finally, the new model SPOC (Small Private Online Course) [4] of online education was produced under the "problem perspective". In addition, there are explorations of mixed teaching systems such as flipped classrooms [5], micro-courses [6], and rain classes [7] in China. The definition of a hybrid teaching system has generally converged on the "collection below the line and online learning" at home and abroad. However, most of the traditional research only focuses on the construction of a mixed teaching system involving both

Project funding: undergraduate education reform project in Shandong province "A Study on the Construction of Mixed Teaching System from the Perspective of Multi-agent” (M2018X248); industry-university cooperation collaborative education project of the Ministry of Education "Innovation of Teaching Content and Practical Conditions of Public Administration Courses under the Perspective of Industry-university Cooperation” (201802202029); teaching reform project of Shandong Normal University "Research on the Construction of Mixed Teaching System from the Perspective of Multi-agent” (2016JG64). teachers and students, ignoring the participation of other subjects. Whether it is SPOC or flipped classrooms, it is just a noun. The essence is the combination of online and offline coordination and coordination of participating entities.

The Triple Helix Theory proposed by Henry Etzkovitz and Loet Leydesdorff provides a new perspective for the construction of a more effective hybrid teaching system - the perspective of multiple subjects [8]. The three-helix theory emphasizes that government, enterprises and universities are the three major elements of the innovation system environment. They are linked according to market requirements, forming a three-helix relationship with three forces intersecting, as shown in Fig.1. From a vertical perspective, the three spirals show an evolutionary form: each spiral is constantly improving and seeking its own development. From a horizontal perspective, this cycle is formed by the flow of several elements, including people, information, and products. For example, the products of the university are mainly graduates, new scientific research results and new ideas. The products of the industry include commodities, taxes and capital, and the government's products include policies, regulations and funds. These elements flow or transfer between universities, industry, and government, forming a cycle of people, information, and product cycles.

Based on the stakeholder theory, Zhang Shiai emphasizes the improvement of the teaching quality of the participation of multiple subjects such as teachers, students and administrative staff [9]. Li Fengqing and Han Xiaoling believe that hybrid teaching advocates joint construction, full participation, and diversified value [10]. However, for the construction of a hybrid teaching system involving multiple subjects, no scholars have proposed specific construction mechanisms or measures, which only involve the marginal parts such as importance and urgency, industry-university integration, and multi-assessment [11]. Based on a new perspective, this paper breaks through the dual-subject framework of the traditional hybrid teaching system and proposes a hybrid teaching system that constructs a multi-subject perspective. This new hybrid teaching system applies information technology, incorporates multiple subjects, combines traditional face-to-face teaching with online teaching, and integrates different teaching concepts, needs, methods, content, and frameworks, covering pre-class, in-class, and after-school. 


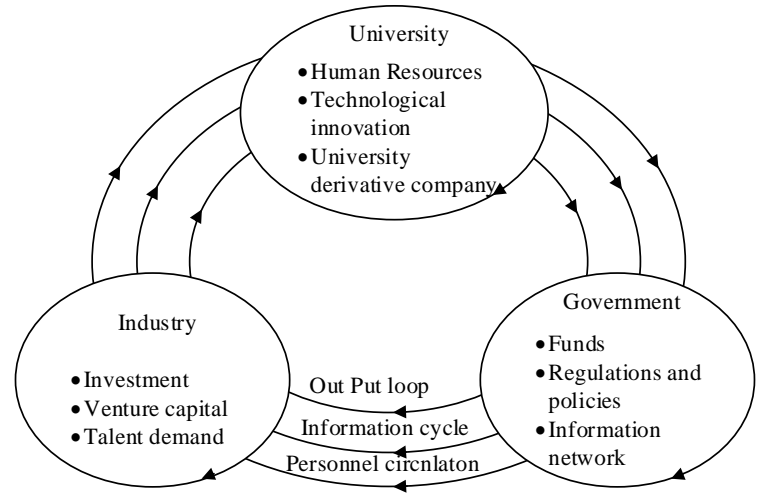

Fig.1. Three Helix Theory

\section{THE FOUR-PARTY CO-CONSTRUCTION MECHANISM}

This paper constructs a four-party co-construction mechanism of mixed teaching system from the perspective of multi-subjects, including government, schools, enterprises and social organizations, and including the whole process, as shown in Fig.2. The government has an authoritative guiding role to guide the construction of a hybrid teaching system. And the government pays attention to whether the construction of a mixed teaching system promotes economic and social development and improves the quality of the people. The department pays attention to whether the hybrid teaching system implements the will of the higher-level administrative department and whether it ultimately promotes the development of the school. Teachers pay attention to whether the hybrid teaching system can improve the teaching achievement and professional title level and realize their social value. Students are concerned about whether it is conducive to knowledge acquisition and future employment. Enterprises paying attention to the construction of a mixed teaching system should consider the needs of enterprises and the development characteristics of enterprises, and hope to cultivate talents in the labor market. Social organizations pay attention to whether the value concept of the organization affects the development of education, and expects the value concept of the organization to become the mainstream value concept of the society. The Specific measures have the following two aspects.

\section{A. Improving the coordination and guarantee mechanism for} the joint construction of the Quartet

Paying attention to the different value demands of multiple subjects and improving the basic guarantees is the key for the four-party co-construction mechanism.

- Relevant policies, programs and documents should be issued to stipulate the objectives, construction tasks, construction requirements, construction steps, guarantee mechanisms and incentives for the construction of mixed teaching courses[12]. It is necessary to introduce relevant policies for the joint construction of the mixed teaching model, and improve the "Multi-participation classroom teaching reform implementation plan" and "mixed teaching curriculum construction management measures" and other documents.

- The specialized institutions built by the hybrid teaching model should be built to clarify the rights and responsibilities between the various entities and coordinate the advancement of all parties. And we can set up a mixed teaching model reform leading group [13], including teachers representatives, student representatives, school department representatives, counterpart enterprise representatives, social organization representatives.

- The government should improve policies and regulations, and actively support and encourage enterprises, institutions, and social organizations to participate in the construction of a hybrid teaching system. And the government should formulate tax reduction and exemption policies, provide preferential policy support, give necessary public financial subsidies, incorporate the construction of mixed teaching systems into the scope of public resource policy support, and create favorable environmental conditions for the joint construction of the mixed teaching system.

- Relevant institutions will carry out mixed teaching mode design training, network comprehensive teaching platform use training and mixed teaching reform promotion training for participating participants. The training should be gradual and continuous throughout the mixed-style teaching system, and gradually let the participants understand and master the mixed teaching mode.

\section{B. Forming the whole teaching process with multi-agent participation}

The hybrid teaching system includes the basic structure, framework, teaching content design, teaching method design, teaching process design and teaching result evaluation process of the teaching process [14]. Multi-subjects should actively participate in the whole process of teaching sequence, process, method, method, form, content, feedback, evaluation, summarization, comparison and derivation.

In the pre-class stage, the participating participants participate in the development of teaching plans, including study guides, specific tasks, problems, etc., and provide various teaching resources such as online, offline and auxiliary for mixed teaching. Secondly, the students complete the learning tasks related to the difficult points of teaching through relevant supporting resources, and submit the confusion encountered in the learning process to the learning platform. Different teachers of different subjects can answer questions for students online and form self-learning feedback before class. This lays the foundation for better interaction between multiple subjects in the class. 


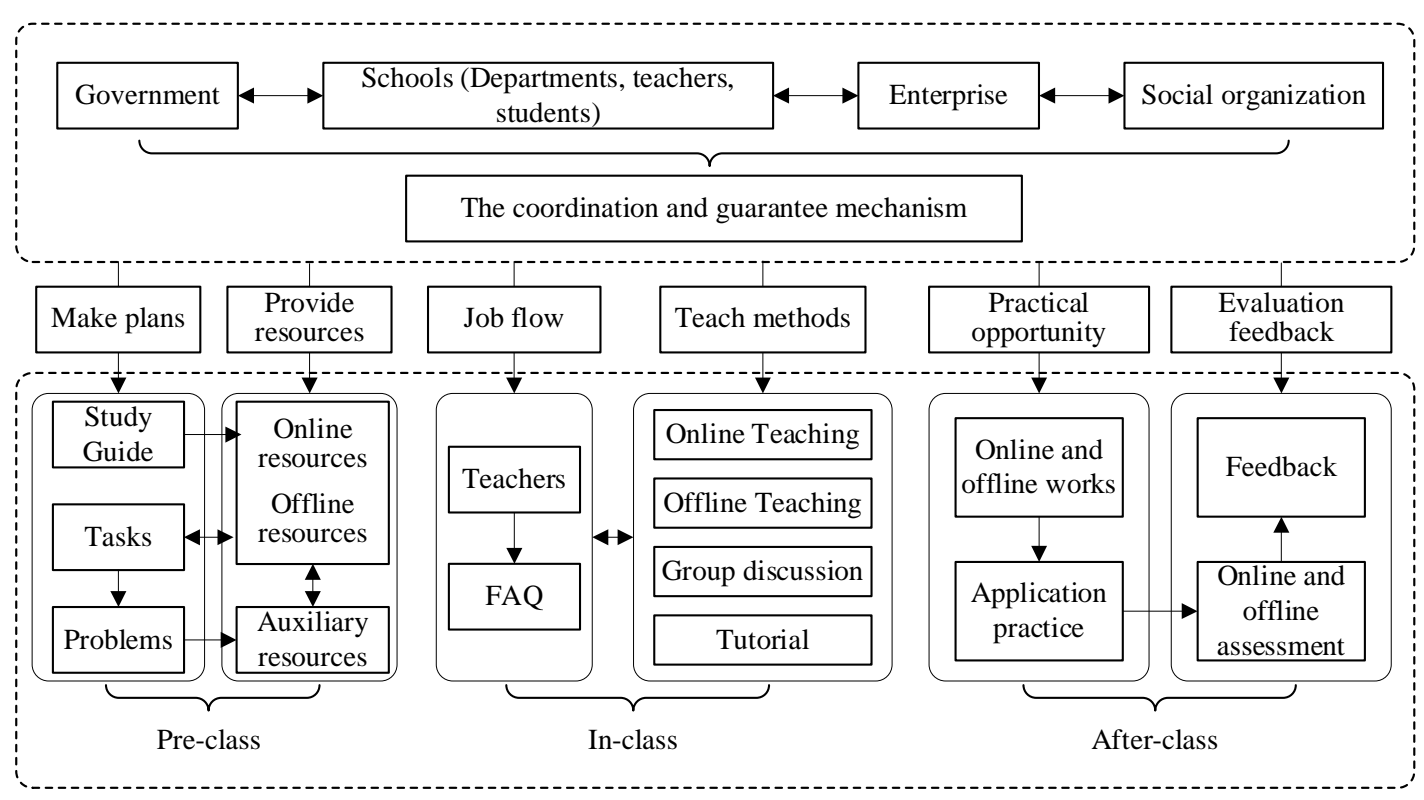

Fig.2. The four-party co-construction mechanism of the hybrid teaching system

The stage of the lesson includes the formation of the teaching team and the process of answering questions and doubts. The team of teachers builds experts and scholars who integrate the subjects of the Quartet, forming a post flow mechanism between multiple subjects and giving play to the advantages of different subjects. A course can be taught by multiple teachers, or multiple teachers with different subjects. Teachers can answer questions about the common problems of online and offline feedback during the task completion process, online resources and face-to-face teaching, and use centralized teaching, organizational discussion or individual guidance to answer questions. In this process, students can display research learning results and share learning experiences and experiences through works exhibitions, time-limited speeches, and debates. In this process, multi-agents should not only comment and guide students' learning outcomes, but also guide students to reflect on the gains in knowledge and skills, and also guide students to summarize the learning process, learning attitude, learning experience, and learning methods, conduct self-evaluation and form self-awareness.

The after-class stage includes four steps: consolidation, practice, evaluation, and feedback. First, students complete online and offline assignments to consolidate their knowledge and skills. Secondly, students participate in the practical opportunities provided by the Quartet and improve their application level. Once again, the Quartet subjects participate in the online and offline evaluation of the entire mixed teaching process, forming a multi-level, all-round evaluation system [15]. Finally, the evaluation results are fed back to all aspects of the hybrid teaching system, and each subject promotes the further optimization and upgrading of the hybrid teaching system.

\section{DifFICUltiES}

The "Opinions on Deepening the Integration of Production and Education" issued by the General Office of the State Council of China pointed out that the supply side and the demand side of the talent cultivation cannot be fully adapted in terms of structure, quality and level, and the problem of "two skins" still exists. As a mixed education reform of social and cultural reform, it is far more difficult than the educational reform as a political and economic reform [16]. The important reason is that multi-subjects have different expectations and value demands for the reform and construction of the hybrid teaching system. There are three difficulties in the practice of building a hybrid teaching system based on the perspective of reality and theory:

First, the participation of multiple entities is less motivating. The multi-participating hybrid teaching system reform is a comprehensive reform in the field of education. It has a heavy task, a wide range of scope, a deep interest, a lot of factors, and a long period of time. It is deeply restricted by the complex factors of politics, economy, culture, and stratum, urban and rural areas, and regions of the external society [17]. These make the multi-participation of the hybrid teaching system a long way to go. In addition, even if an incentive system combining the incentives and external incentives within the multi-subject is formed, there is a huge shortage of funds.

Second, the participation of multiple subjects in the teaching process is not sufficient. On the one hand, "formalism" continues to exist. In the process of participation in enterprises, industries, and social organizations, they only stay in the form of "listing" and "lectures" and do not go deep into the substantive aspects of the whole process of the hybrid teaching system [18]. Their provision of practical positions and practice bases also become furnishings, and there is no organic interaction between the subjects. On the other hand, the hybrid teaching system introduces multiple and diverse technologies 
and resources, but the phenomenon of multimedia infusion "needs to be further changed.

Third, there is a lack of coordination of rights among participating entities. Although there is a right coordination mechanism between the subjects, the change of consciousness, role, absence, and voice still take a long time. Coordination between subjects is a complex and critical link, not a one-step process. How the government guides the promotion of coordination among various entities needs further study. How to promote the effective participation of the government, schools, enterprises and social organizations, and form a long-term mechanism for the coordination of various entities to be further explored.

Along with the development of social governance and network governance with multiple participation[19], a comprehensive mixed teaching system involving multiple subjects will be formed to drive the exploration and practice of a new round of teaching reform.

\section{CONCLUSIONS}

The era of technological change education has arrived. From digital education to wisdom education, from single-subject education to multi-subject education, building a hybrid teaching system has become an important trend in global education development. There are mixed teaching forms such as AOC, OCW, MOOC, SPOC, and flipped classroom, micro-course and rain classroom. But there are still some shortcomings in breaking the barriers to space, coordinating multi-agent teaching and the needs of multiple subjects. Whether it is SPOC or flipped classrooms, it is just a noun. The fundamental of the hybrid teaching system is the coordination of the interests of the participating parties.

Based on the three-helix theory proposed by Henry Etzkowicz and LoetL eydesdorff, this paper proposes a four-party co-construction mechanism of the hybrid teaching system based on the new perspective of multi-subjects. A coordinated guarantee mechanism involving schools (departments, teachers, students), enterprises, governments, and social organizations should be formed to build a digital learning community and a hybrid teaching system across schools, multi-subjects, and the whole process. In addition, the multi-agent coordination and participation in the construction of the hybrid teaching system is not a one-time process. The change of consciousness, role and discourse power still takes a long time, and the process inevitably has some difficulties in enthusiasm, participation and coordination. We must carry out reforms step by step. This article provides a practical and theoretical basis for educational reform, which is conducive to the improvement of the education system and the cultivation of top talents. But its difficulties need to be overcome, and the practical results need further research and verification.

\section{REFERENCES}

[1] R.A. Majeski, M. Stover, J. Ronch, "Making asynchronous online learning more learner-oriented: an integrated conceptual model with applications for course design and instruction”, Educational Gerontology, Vol. 42, pp. 109-119, February 2016.

[2] B. Ceylan, M.M. İnceoğlu, "Learning environments: Ege university open course ware project (EUADM)", Procedia-Social and Behavioral Sciences, Vol. 2, pp. 4172-4176, February 2010.

[3] V. Kovanović, S. Joksimović, O. Poquet, T. Hennis, I. Čukić, P.D. Vries, M. Hatala, S. Dawson, G. Siemens, D. Gašević, "Exploring communities of inquiry in massive open online courses”, Computers \& Education, Vol. 119, pp. 44-58, April 2018.

[4] B.J. Lockhart, N.A. Capurso, I. Chase, M.R. Arbuckle, M.J. Travis, J. Eisen, D.A. Ross, "The use of a small private online course to allow educators to share teaching resources across diverse sites: the future of psychiatric case conferences?”, Academic Psychiatry, Vol. 41, pp. 81-85, January 2017

[5] X.Y. LIN, J.S. PAN, "Design and implementation of hybrid teaching mode based on flipped classroom". China Vocational and Technical Education, No. 2, pp.15-20, January 2016. (In Chinese)

[6] H. Yang, Y.F. Fu, "The practice and effect analysis of hybrid teaching based on micro-class", China Vocational and Technical Education, No.17, pp. 45-49, June 2017. (In Chinese)

[7] D. Kim, M. Yoon, I. Jo, R.M. Branch, "Learning analytics to support self-regulated learning in asynchronous online courses: a case study at a women's university in South Korea”, Computers \& Education, Vol. 127, pp. 233-251, December 2018.

[8] E. Mêgnigbêto, "Modelling the triple helix of university-industry-government relationships with game theory: core, shapley value and nucleolus as indicators of synergy within an innovation system”, Journal of Informetrics, Vol. 12, pp. 1118-1132, April 2018.

[9] S.A. Zhang, "Bottlenecks and countermeasures: teaching quality management in colleges and universities based on stakeholder perspective", Heilongjiang Higher Education Research, No.10, pp. 20-22, October 2014. (In Chinese)

[10] F.Q. Li, X.L. Han, "Construction and practice of hybrid teaching quality evaluation system", China Electrochemical Education, No.11, pp. 108-113, November 2017. (In Chinese)

[11] Q. Liu, "Reconstruction of value concept and behavior model of teaching quality assurance system in China”, Jiangsu Higher Education, No.2, pp. 12-17, February 2018. (In Chinese)

[12] J. Ren, "Research on the reform and promotion strategy of mixed teaching mode in colleges and universities", Modern Educational Technology, No. 4, pp. 74-78, April 2017. (In Chinese)

[13] L.Y. Chen, "Research on the Construction of Basic Teaching Governance Structure under the Background of Multi-agent Participation”, Teaching and Management, No.21, pp. 29-31, July 2017. (In Chinese)

[14] F.Q. Li, "Theoretical foundation and teaching design of mixed teaching". Modern Educational Technology, Vol. 26, pp.18-24, September 2016. (In Chinese)

[15] M. Lu, Y.Q. Nie, "Construction of multi-evaluation system for vocational education”. Higher Agricultural Education, No. 5, pp. 94-97, May 2014. (In Chinese)

16] T.J. Cheng, "Reform education reform-from political-economic reform to social-cultural reform”, Journal of Educational Science of Hunan Normal University, Vol. 11, pp.15-20, March 2012. (In Chinese)

[17] F.Q. Li, X.H. Wang, J.M. Zhao, "Top-level design and implementation strategy of hybrid curriculum construction project-taking Shandong Normal University as an example”, Modern Educational Technology, Vol. 28, pp.32-38, June 2018. (In Chinese)

[18] J. Zhang, "On the governance of multi-subjects in school-enterprise cooperation”, China Vocational and Technical Education, No. 18, pp. 44-49, June 2018. (In Chinese)

[19] X.M. Yang, S.S. Tang, J.H. Li, "Development of education big data: connotation, value and challenges”. Modern Distance Education Research, No. 1, pp. 50-61, January 2016. (In Chinese) 